\title{
UMA ABORDAGEM CRÍTICA DO CONCEITO DE "ETNICIDADE" NA OBRA DE FREDRIK BARTH*
}

Diego Villar

\section{Introdução}

Como Van Gennep, ou o próprio M arx, Fredrik Barth é um dos autores mais citados e, contudo, menos lido pelos antropólogos. Um exemplo dessa ambivalente devoção se encontra no trabalho recente de Françoise M orin e Bernard Saladin D'Anglure (1997). Os dois entusiastas do norueguês afirmam, sem maiores constrangimentos, que a teoria barthiana da etnicidade assentou as bases para "uma ruptura epistemológica" (1997:161) na antropologia - embora, para sustentar tal juízo, não tenham necessitado ir além das quarenta páginas da famosa "Introdução" a Ethnic groups and boundaries 1 . Não obstante, a influência da obra de Barth parece irrefutável. Inúmeros trabalhos evocam, confessada ou dissimuladamente, sua obra mais conhecida. $\mathrm{Na}$ opinião de Talal Asad (1972:74), a análise de Political leadership among the Swat Pathans (1990 [1959]) é "magnífica" e merece ser considerada "um clássico moderno"; para A dam Kuper (1983:143), Barth foi uma das figuras mais "cheias de vida" da antropologia social britânica dos anos 50 e 60. No entanto, a acolhida da obra barthiana nem sempre foi tão unânime e fervorosa. $O$ mesmo A sad, logo após o citado elogio ao rigor (1972), dedicou páginas inteiras a criticar o magnífico clássico moderno; e um dos antigos mestres de nosso autor em Cambridge, o imprevisível Sir Edmund Leach, outorgou-Ihe o obscuro estatuto de "um clássico menor": embora a obra do norueguês tenha sido "estimulante" em sua época, "já não constitui um foco central de interesse intelectual" (Leach 1982:271).

Indo além das opiniões diversas, o certo é que as teses de Barth suscitaram grandes discussões, transformando-se em um marco para a disciplina (Wallman 1991; Cohen 1978; M orin e Saladin D'Anglure 1997). Contudo, falar da "Obra" de Fredrik Barth não é tarefa isenta de dificul- 
dades. N ote-se que nos referimos a ela como um todo, enquanto, na maior parte dos trabalhos mencionados, a discussão se concentra em um único texto, elevado por mérito próprio à categoria de clássico, apesar da ironia de Leach: a "Introdução" a Ethnic groups and boundaries (1976a). Não nos surpreende a imensa importância com freqüência atribuída a este texto - ele, com efeito, pareceria ser o paradigma, o símbolo, o arquétipo das preocupações barthianas. O notável é que, paradoxalmente, ele não pareça nem tão típico nem tão representativo se, tomando sua obra como uma totalidade, o compararmos a outros escritos do norueguês. Ao contrário, revela-se árido, repetitivo, monótono e mesmo tedioso - sem falar de sua infeliz tradução para o espanhol. O que não deixa de ser curioso, pois, em geral, Barth escreve em uma prosa clara, ordenada, estruturada em frases breves, contundentes e precisas; em uma língua austera, por vezes elegante, totalmente despojada de jargão, que não se deixa tentar por grandes floreios; em um estilo, em suma, livre de ambições pseudoliterárias. As descrições jamais se estendem além do estritamente necessário, os capítulos são incisivos e sucintos, o ordenamento lógico e o desenvolvimento expositivo de seus livros mostram-se transparentes, e os argumentos, igualmente impecáveis, são sempre resumidos em um detalhado parágrafo final. Por isso, se a "Introdução" parece ser tematicamente coerente com os interesses de nosso autor, tal como estes aparecem em outros escritos, não seria, por outro lado, ao menos em um certo sentido, descabido vê-la como um texto excepcional dentro do corpus barthiano. Não se trata, de modo al gum, de menosprezar sua importância, mas simplesmente de contextualizá-la em relação ao trabalho de Barth, demonstrando que a concepção de etnicidade não surgiu em um vazio.

Chamaremos a atenção para duas idéias capitais da teoria barthiana que tiveram destinos diferentes. Embora uma delas tenha sido comentada e elogiada à exaustão - a teoria formal ou relativista da identificação étnica - , a outra foi esquecida com um entusiasmo inversamente proporcional. Trata-se da influência dos condicionantes materiais da etnicidade, em especial os fatores ecológicos e demográficos. A pesar de sua sorte diversa, em última instância ambas as noções dão lugar, ou se subordinam, a uma terceira: o problema do ator racional, uma autêntica idéia-mestra, uma premissa que implica, em Barth, não só uma sociologia, como uma determinada concepção do ser humano e de suas obras. 


\section{Os condicionantes ocultos da etnicidade: o fator ecológico e a demografia}

Quando se revisita a argumentação de Barth a respeito da etnicidade, chama a atenção seu apelo constante e sistemático às perspectivas denominadas "ecológica" (1976a:23) e "demográfica" (1976a:24). Ecologia e demografia são fatores cruciais que determinam o êxito ou o eventual fracasso das opções, das decisões e das estratégias relativas à identidade étnica. No prólogo da monografia sobre os Basseri (1986 [1961]), por exemplo, Barth não só declara que empreenderá sua análise "em termos de um ponto de vista ecológico geral", mas também que isto se deve à natureza do próprio objeto de estudo. As características da organização nômade, em sua maioria, "estão interconectadas em termos das possibilidades e restrições implicadas na adaptação pastoril". Por vezes, o norueguês é ainda mais taxativo: "Tentarei deduzir as distintas formas de organização dos processos básicos pelos quais [os Basseri] se mantêm e se adaptam ao meio" (1986:ii). Essas variáveis, porém, não foram muito discutidas pelos críticos, apesar de encarnarem as pretensões mais fortes do modelo barthiano, ao envolverem fatores objetivos que não teriam até então - segundo nosso autor - recebido a devida atenção.

Vejamos mais detalhadamente, para começar, a incidência do fator ecológico. A consideração mais exaustiva a seu respeito aparece em um dos primeiros artigos de Barth, onde, depois de proclamar a importância desse elemento para "a forma e a distribuição das culturas", o autor apregoa a utilização de alguns conceitos da "ecologia animal" para compreender a natureza dos grupos étnicos (1956:1079). Por exemplo, o “nicho" é o locus concreto de um grupo no ambiente, caracterizado não só por suas relações com os recursos naturais, mas também por seus vínculos com os outros grupos co-residentes na área, que serão seus eventuais competidores. É importante lembrar essa definição, que se mantém como premissa inalterada ao longo das sucessivas argumentações barthianas². De seus estudos ecológicos, Barth deduz quatro postulados fundamentais (1956:1088):

1) a distribuição dos grupos étnicos não é controlada por "áreas naturais" fixas e objetivas, mas pela distribuição em nichos específicos, que cada grupo explora mediante sua organização política e econômica;

2) distintos grupos étnicos irão se estabelecer em co-residência em uma área, caso explorem diferentes nichos e, especialmente, caso constituam entre si relações "simbióticas"; 
3) se diferentes grupos étnicos exploram os mesmos nichos, espera-se que o mais poderoso em termos militares acabe suplantando o mais fraco;

4) se diferentes grupos étnicos exploram os mesmos nichos, mas o mais fraco dentre eles é capaz de explorar os ambientes, recursos e climas marginais, coexistirá com os outros na mesma área sem maiores problemas.

Em suma, diferentes grupos étnicos têm, compartilhando uma mesma zona, distribuições e fronteiras superpostas, fluidas. Em outras palavras, relacionam-se em um continuum de vínculos que vai desde a mera co-residência - como ocorre com dois dos vizinhos dos Pathan, os Gujar e os Kohistani - até a simbiose ritual, econômica ou política - pressuposta, por exemplo, no sistema de castas (Barth 1971). A quádrupla conclusão de Barth poderia ser resumida, sem nos arriscarmos demasiado, na fórmula a "sobrevivência do (grupo étnico) mais apto". No tocante à etnicidade, importa destacar, por ora, que os aspectos ecológicos são alguns dos muitos "fatores" que - conforme requeira a argumentação "condicionam", "determinam" ou simplesmente "influem" nas opções étnicas dos sujeitos.

O exame barthiano da ecologia, contudo, normalmente, é bastante enxuto. Em um estudo sobre parentesco, define-se "o que poderíamos, de modo geral, chamar de ecologia" como sendo aquelas "situações concretas da vida surgidas quando se perseguem certos propósitos sob restrições técnicas e práticas" (Barth 1973:9). No trabalho antropológico que julgo ser o mais refinado de Barth, o tratamento da "ecologia" de Swat mal chega a ocupar três páginas. Trata-se da típica resenha sobre o ambiente apresentada pelas grandes etnografias tradicionais. A pós mencionar, em uma abordagem panorâmica, a topografia, as vias de comunicação, o clima, a vegetação e as condições nativas para a agricultura e a criação de gado (Barth 1990:5-7), o livro flui com tranqüilidade, sem necessidade alguma de se referir aos condicionantes ecológicos da existência humana. De fato, a argumentação sobre os "recursos naturais" articula-se melhor ao processo de divisão periódica da terra entre os grupos agnáticos pakhtun e a seu posterior "congelamento", quando do surgimento do Estado nacional - ou seja, aos usos sociais da terra.

A tese ecológica torna-se mais imaginativa em uma obra posterior, na qual a relação do ambiente com a vida social dos grupos pastoris do sul da Pérsia aparece como recurso conceitual e metodológico constante. A morfologia, com seu padrão sazonal de atividades e sua influência nos ciclos migratórios, a natureza da atividade pastoril, com seu influxo na administração do espaço, a economia, a produção e a própria dieta dos 
Basseri, todos são fatores que Barth vincula de maneira convincente à sua explicação das unidades domésticas, do parentesco e da aliança, das divisões segmentares da organização social e dos mecanismos políticos e de chefia (Barth 1986). A título de exemplo, detenhamo-nos no tratamento das práticas rituais. Seguindo Leach, Barth argumenta que os antropólogos costumam incorrer no preconceito naïf de considerar distintos os aspectos "técnicos" e "simbólicos" do rito. Como conseqüência, supõem que a importância técnica ou material de um ato determinado implica que sua densidade simbólica esteja "alhures". Entre os Basseri, a vida "religiosa", no sentido clássico, é comprovadamente pobre. Mas Barth descobre que tal ascetismo se deve às categorias da descrição antropológica; na verdade, "o rito central da sociedade nômade" é o próprio ciclo anual de migrações, capaz não apenas de fornecer o modelo para interpretar e conceituar o espaço-tempo, mas dotado também de uma alta carga valorativa e emocional. O "valor" não se expressa por meio de "parafernália exótica" nem de "atos simbólicos desnecessários". É próprio dos Basseri exprimir valores e símbolos mediante suas atividades adaptativas, mediante suas relações com a ecologia (Barth 1986:146-153)3.

Nos escritos posteriores, a abordagem da ecologia cultural parece terse tornado fundamental mente programática. Leach, em uma ácida resenha, criticou seu aluno por não ter ido suficientemente longe na utilização dos conceitos ecológicos, já que isto Ihe teria permitido evitar algumas dificuldades na abordagem do sempre espinhoso dilema dos modelos analíticos e de sua adequação aos fatos empíricos (Leach 1982:272-273).

Por fim, à parte as considerações sobre o ritual basseri - com as quais se pode estar de acordo ou não, mas que ao menos aportam argumentos relativamente novos - , dificilmente pode-se resistir à tentação de um julgamento taxativo. A versão barthiana da "ecologia cultural" praticamente não ultrapassa o senso comum e, com notável freqüência, reduz-se a postular que grupos étnicos coabitando em um mesmo nicho ecológico estabelecem relações de interdependência, complementaridade e simbiose, ou então de competição e inimizade. Não negamos tal afirmação, pois seria difícil fazê-lo, mas não chegamos a compreender onde está o especificamente ecológico nesse tipo de explicação. Em segundo lugar, a direção das supostas "influências", "condições" ou "determinações" ambientais não fica muito clara: embora, como vimos, Barth declare terminantemente, em reiteradas ocasiões, que o meio "determina" ou "condiciona" as formas sociais de organização, outras vezes a linha de força se inverte, se dilui ou se torna perigosamente ambígua4. O leitor se vê forçado a concluir que a apreciação do ambiente e de suas implica- 
ções não parece nem expositiva nem metodologicamente mais necessária, intensiva ou significativa do que os estudos apresentados pelos veIhos africanistas como "introdução" a suas monografias5.

Igualmente ou mais decepcionante é a variável "demográfica”. Além de advertir que o analista "não pode passar ao largo dos problemas de número e equilíbrio" ao estudar os grupos étnicos, Barth limita-se à afirmação - dificilmente refutável - de que, em termos metodológicos, é conveniente levar em conta os fatores demográficos na conformação e na manutenção das fronteiras, pois entre elas pode haver "osmose" e "trânsito de indivíduos" (Barth 1976a:25). O tratamento é menos inócuo na etnografia basseri. Para que a organização social dos nômades se mantenha, "pelo menos relativamente estável", ela deve desenvolver com o ambiente uma espécie de equilíbrio não apenas ecológico e demográfico, mas também econômico e político (Barth 1986:113-114). Quanto ao "equilíbrio demográfico" propriamente dito, certos fatores são "tanto biológicos quanto sociais": a fecundidade, o controle da natalidade, a mortalidade, a migração e a sedentarização. Por exemplo, pode-se constatar que, para continuar existindo em face de um incremento constante da natalidade (i.e., a "entrada" de pessoas no sistema), o modelo nômade de organização social deve "contrabalançar" tendências contrárias, como a sedentarização ou as migrações (i.e., a "saída") (1986:116-121)6.

\section{A etnicidade na teoria dos grupos étnicos e suas fronteiras}

Nos textos iniciais de Barth não há menção explícita à "etnicidade". M ais tarde, no livro sobre os Basseri, o autor sugere que se costuma incorrer no erro de considerar a linguagem o fator "definidor" da identidade étnica, e que o mesmo ocorre com os etnônimos e os gentílicos, freqüentemente derivados de problemas de observação ou de tradução. No caso dos nômades persas, os atributos "definidores" mais importantes, em lugar da língua ou das narrativas de origem, são os alinhamentos em unidades políticas abrangentes (Barth 1986:100-ss.). Barth, deve-se notar, ainda avalia quais são os "fatores" ou "traços" culturais - os "diacríticos", dirá depois - que "definem" o pertencimento étnico; não discute se eles existem, ou se devem existir, ou se, caso existam, importam ao observador. A concepção da etnicidade não alcançara o refinamento a que haveria de chegar.

O texto emblemático no qual Barth codifica sua teoria - e, como dissemos, a representa metonimicamente para o leitor de antropologia - é a famosa "Introdução" a Ethnic groups and boundaries. A premissa é a 
de que a idéia de "grupo étnico" não define uma "sociedade" e, menos ainda, uma "cultura". De fato, boa parte da argumentação consiste em distinguir a "organização social" da "cultura" 7 . O grupo étnico é o "sujeito" da etnicidade: embora possa haver grupos que compartilhem uma mesma cultura, as diferenças culturais não conduzem à formação ou ao reconhecimento de grupos étnicos distintos. Para Barth, o fato de compartilhar uma cultura é uma conseqüência, não a causa, a condição ou, menos ainda, a explicação da etnicidade.

No coração do modelo encontra-se o conceito de "sociedade plural" de Furnivall, uma sociedade colonial multicultural em que cada um dos grupos constituintes mantém sua religião, sua língua e sua cultura, mas na qual todos se relacionam na situação comum do mercado (Furnivall 1991; Barth 1986; 1990). Uma vez mais, pressupõe-se um cenário onde diferentes grupos interagem, definindo, por meio desse mesmo contato, a natureza e o alcance de suas relações recíprocas. Sem a preocupação de ter de rastrear "unidades étnicas correspondentes a cada cultura", Barth (1976a:9), evita restringir-se àquelas ilhotas isoladas e discretas que obcecavam a velha antropologia:

Previamente, a antropologia se havia limitado a estudar povos indígenas em termos de sua organização social ou cultural, como se fossem isolados e independentes. Dedicou-se pouca reflexão às relações que mantinham com o ambiente econômico e social a seu redor. Tampouco se deu muita atenção à maneira como viam a si mesmos, ou como seus vizinhos os percebiam (M orin e Saladin D'Anglure 1997:159).

O norueguês desloca o interesse analítico dos próprios grupos étnicos para a criação e a persistência de suas interfaces, suas fronteiras, suas relações, e é suficientemente explícito ao qualificar a empreitada como "uma investigação empírica do caráter dos limites étnicos" (Barth 1976a:9).

O argumento recorda o tratamento dos fatores ecológico e demográfico. Do primeiro, retoma-se a noção de um meio no qual prima o contato — ou a franca competição - entre grupos étnicos; do segundo, a idéia de que existe um "trânsito" ou uma "osmose" através de seus limites. No entanto, o ponto novo, devo deixar claro, é o fato de não haver unidades sociais preexistentes a se vincular posteriormente umas às outras. A própria relação as constitui como tal: “Em outras palavras, as distinções étnicas não dependem de uma ausência de interação e reconhecimento social; pelo contrário, geralmente estas são o próprio fundamento sobre o 
qual estão construídos os sistemas sociais que tais distinções contêm" (Barth 1976a:10). A análise deve ser "gerativa" e não pode limitar-se a explorar a conservação ou a persistência dos grupos étnicos, mas tem de procurar esclarecer a dinâmica incessante de conformação e reestruturação dos mesmos (1976a:11).

A mudança de perspectiva pareceria revelar uma modificação de ordem ontológica. Os grupos étnicos não são unidades sociológicas discretas nem unidades sociais estruturadas em torno de traços culturais distintivos, "portadores" da especificidade grupal. Barth critica a "definição de tipo ideal" de grupo étnico (Barth 1976a:11), ou seja, o inventário indutivo de uma série de conteúdos culturais como territórios, línguas, costumes ou valores comuns ${ }^{8}$. Esta visão pressupõe, primeiro, uma equação errônea (uma raça = uma cultura =uma linguagem = uma sociedade); segundo, supõe que essa formação discreta seja o "sujeito" ou o "ator" social, responsável por aceitar, recusar ou discriminar outras formações similares. Os grupos étnicos são, ao contrário, categorias adscritivas nativas, que regulam e organizam a interação social dentro e fora do grupo, sobre a base de uma série de contrastes entre o "próximo" e o "distante". Tais contrastes se "ativam" ou não segundo os requisitos do contexto. A manutenção das fronteiras da etnicidade não resulta do isolamento, mas da própria inter-relação social: quanto maior a interação, mais potente ou marcado será o limite étnico. Não somente o contato com outros grupos, mas também o vínculo com o ambiente influi para que, em um contexto determinado, se ative ou não uma categoria étnica: “Certamente, um mesmo grupo de indivíduos, com suas próprias idéias e valores, posto diante das diferentes oportunidades oferecidas por diferentes meios, se veria obrigado a adotar diferentes padrões de existência e a institucionalizar diferentes formas de conduta" (1976a:13-14). Os critérios de reconhecimento podem mudar e, com freqüência, o próprio grupo pode mudar. No entanto, o fato formal da distinção entre membros e nãomembros subsiste. Daí a célebre definição: “Os grupos étnicos são categorias adscritivas e de identificação, que são utilizadas pelos próprios atores e têm, portanto, a característica de organizar a interação entre os indivíduos" (Barth 1976a:10-11).

Na prática, as categorias étnicas são uma "forma de organização social", termo que Barth entende como a situação na qual "os atores utilizam as identidades étnicas para categorizar a si próprios e a outros, no propósito de uma interação" (Barth 1976a:15). A auto-inclusão e a inclusão por parte dos outros são os elementos fundamentais. A etnicidade não pode depender de uma única definição geral. Não se decifra um ca- 
tálogo de diferenças objetivas, "mas somente aquelas que os próprios atores consideram significativas" em cada contexto específico (1976a:15; ênfase minha). Tampouco se deve procurar uma lista imutável de traços ou se pode dizer quais as características que serão sublinhadas e quais não o serão: al gumas serão utilizadas como sinais e emblemas de diferença, seja como "diacríticos" manifestos (indumentária, linguagem etc.) ou como "orientações de valores básicos" (normas de moralidade e excelência pelas quais se julga a ação). Trata-se de "um recipiente organizacional capaz de receber diversas proporções e formas de conteúdo nos diferentes sistemas socioculturais" (1976a). N ota-se aqui uma certa qualidade "formal" do modelo: o que interessa não é o "conteúdo" cultural, mas o "limite" negociado pelo grupo em contextos precisos, ao desenvolver sua interação com os demais. Os aspectos que assinalam a fronteira étnica podem mudar, mas subsistirá - ao menos enquanto convenha, como veremos - a dicotomia entre membros e não-membros.

O consenso grupal a respeito de códigos e valores não costuma se estender além das ocasiões específicas nas quais se interage. Em outras palavras, só há "etnicidade" em contextos bem definidos. Este aspecto "deve ser geral para todas as relações interétnicas" (Barth 1976a:18). No entanto, sublinha Barth, se em al gumas interações concretas os diacríticos às vezes se acentuam, em outras sua manutenção pode se mostrar "inconveniente". Esta questão - a de saber o que é conveniente ou não e a quem cabe julgá-lo - é o problema capital.

\section{0 problema do ator racional}

A singularidade da abordagem de Barth, não só da etnicidade, mas de todos os fenômenos sociais, não advém de seu apelo a determinismos naturais nem - ao contrário do que freqüentemente se pensa - do aspecto relativo ou formal da etnicidade. O quid não é o vago recurso ao ambiente ou à demografia nem a visão "relacional" do pertencimento grupal que, na verdade, foi antecipada por Evans-Pritchard, Dumont e toda a plêiade estruturalista. $O$ cerne é o que poderíamos chamar de "problema do ator racional". Ou seja, quem é o sujeito, o "eu", ou melhor, o "nós" da etnicidade; e, em especial, quando e por que ele entra em cena. Em um artigo de 1967, Barth explica a mudança social nos seguintes termos:

Aquilo que as pessoas querem obter, os fins variados que perseguem, fornecem a orientação para sua conduta. Por outro lado, as restrições técnicas e 
ecológicas condenam al guns tipos de conduta ao fracasso e recompensam outros, enquanto a presença de outros atores impõe restrições estratégicas e oportunidades que modificam as escolhas favoráveis que as pessoas podem fazer (Barth 1967:663).

Estas linhas contêm o germe de todas as preocupações barthianas. Reaparece a velha preocupação com a sobrevivência do (comportamento) mais apto, com o êxito ou o fracasso da ação que deve superar as restrições, tanto naturais (ecológicas e demográficas) quanto interacionais (os outros atores), impostas pelo meio. M as agora o interesse se desloca para o fato de que os condicionamentos influem não tanto sobre o ator, mas sobre suas ações, suas escolhas, suas decisões, suas condutas. Estas, em cada contexto específico, conforme se ajustem ao meio, comportam ou não determinados "benefícios" 9 .

\section{Influências}

Detenhamo-nos um momento para deixar bem claro em que consiste a racionalidade da free choice barthiana (Barth 1990). Todas as explicações de Barth podem ser traduzidas com facilidade para a linguagem das teorias da ação - ou, em termos sociológicos, para uma análise que, ao buscar o "sentido" da conduta do ator individual, parte de suas metas e expectativas. M as não se trata, além disso, de qualquer ação, e sim de um modo de agir bem determinado, localizado, sem rodeios, no plano da racionalidade weberiana voltada para os fins (Zweckrationell), da "razão instrumental" de Parsons ou, remontando um pouco no tempo, da "ação lógica" de Pareto. Trata-se de uma avaliação crítica baseada no cál culo de custos e benefícios, no interior de um contexto explícito de meios e finalidades (Weber 1993; Parsons 1968). Nessa ênfase tão marcada na atividade racional do indivíduo, nessa defesa sistemática do poder da racionalidade e da ação dos atores, nesse choque tão frontal contra os diversos avatares do funcionalismo, encontramos um universo coerente de idéias, cuja origem podemos rastrear em pelo menos três influências intelectuais distintas. Essas tradições, apesar de suas procedências aparentemente desconexas, se articulam de modo decisivo em Barth.

Em primeiro lugar, temos a influência - tipicamente escandinava - de pensadores como Hans Albert, von Wright ou J ohn Elster, todos opostos ao(s) funcionalismo(s), todos defensores de sociologias, filosofias ou mesmo A ntropologias - com "A" maiúsculo - que revelam por trás dos atos humanos a racionalidade ou as racionalidades do indivíduo e de 
sua ação ${ }^{10}$. Também se pode mencionar aqui a teoria da escolha racional mais sofisticada, segundo a qual os atores se relacionam perseguindo metas específicas e bem definidas, ao otimizarem os meios, avaliarem alternativas, maximizarem seus problemas e calcularem custos e benefícios.

Em segundo lugar, observamos em Barth traços claros da influência parsoniana. Mais precisamente, da teoria "voluntarista" da ação (Parsons 1968). Parsons tentou reconciliar a ação individual e a estrutura social, embora, a crer em seus críticos, tenha terminado por sacrificar a primeira no altar da segunda. Talvez pareça estranha essa relação com o sociólogo americano, que é, afinal, uma espécie de campeão do funcionalismo. Contudo, acima dos requisitos e das necessidades dos sistemas e dos subsistemas, a ação é, para Parsons, uma conduta ou um comportamento "dirigido" por certos significados, símbolos ou valores atribuídos às coisas pelos atores, e a categoria mais importante da ação é a interação, a "ação social" weberiana, aquela que leva em conta as vontades, as necessidades ou as metas dos outros atores. Nos termos desse marco conceitual, supõe-se de maneira mais ou menos implícita que as distintas expectativas se ajustam, ou (em termos mais modernos) se negociam, ou (como está em moda dizer) se reinterpretam mutuamente. A pesar do caráter algo intrincado da lógica parsoniana, o que importa é que os atores de Barth — os quais, em busca de determinadas metas, escolhem certas condutas para alcançá-las, enfrentando restrições impostas pelo meio (natural e social) - lembram muito os "atores" ou as "personalidades" a quem cabia, nos unit acts de Parsons, levar adiante a ação social (i.e., as configurações mínimas nas quais ocorre a ação: meio/s concreto/s, fim/ns concreto/s, condição/ões concreta/s) (Parsons 1968).

Em terceiro lugar, não podemos ignorar a localização da obra de Barth dentro da antropologia social britânica ou, mais precisamente, dentro de uma de suas vertentes. Nosso autor inscreve-se em uma corrente de grande influência, que podemos remontar até Malinowski, passando, sem maiores problemas exegéticos, por Raymond Firth e Edmund Leach, mentor do norueguês em Cambridge.

Nas obras de M alinowski, pode-se identificar três temas tão cruciais quanto recorrentes. Primeiro, a idéia de que, para ser bem compreendido, um aspecto de uma cultura não pode ser estudado isoladamente, mas apenas em seu contexto - em particular, em seu contexto de uso. Segundo, a idéia de que não podemos confiar nas racionalizações das pessoas nem nas regras e normas - ou, em outras palavras, de que as pessoas sempre dizem ou pensam uma coisa e fazem outra. Terceiro, a noção de que, se compreendermos o que os atores realmente fazem e os situarmos em um 
contexto adequado, reconheceremos que suas ações são tão racionais, ou ao menos tão razoáveis, quanto as nossas. $O$ objeto de estudo malinowskiano é, pois, o indivíduo racional, que calcula, avalia e manipula as possibilidades em seu próprio benefício11. Para além das investidas contra o Homo economicus, em Crime and custom in savage society o polonês também observa: "Quando o nativo puder evadir suas obrigações sem perder prestígio ou prejudicar seus ganhos almejados, ele o fará, exatamente como um homem de negócios civilizado". Veremos logo como os trabalhos de Barth repetem integralmente o argumento: os líderes pattan têm as mesmas motivações de seus homólogos ocidentais e se comportam como eles; a família basseri é exatamente igual à família ocidental etc.

De raízes durkheimianas, as teses estrutural-funcionalistas mais exacerbadas enfatizavam, na terminologia de Radcliffe-Brown, as "pessoas" por sobre os "indivíduos". Em suas versões "más", elas imaginavam um mundo de autômatos passivos a obedecer cegamente as normas sociais. Nas variantes "boas", celebravam a racionalidade dos sistemas. Longe de tudo isso, Malinowski e muitos de seus discípulos optaram (como bons atores racionais) por se dedicar à análise das tensões entre os interesses individuais e a ordem social, estudando a ambigüidade das regras e as contradições entre distintos imperativos sociais, analisando a manipulação individual dos sistemas políticos e comprazendo-se com a racionalidade das escolhas, das estratégias e das opções individuais. Essa influência é patente nos trabalhos de Philiys Kaberry, Audrey Richards e Lucy $M$ air, pesquisadoras malinowskianas de primeira hora, e ainda mais em Firth, cujo interesse obsessivo pela tomada individual de decisões era proverbial (Firth 1949, Kuper 1983:134), em Isaac Schapera, cuja análise da liderança política é seguida ao pé da letra por Barth, e em Edmund Leach - o Leach de segunda a sexta-feira, o de Sistemas políticos da AIta Birmânia ou Pul Eliya, não o estruturalista dos fins de semana12. O mesmo se poderia dizer de boa parte da obra de outros grandes antropólogos de Cambridge: M eyer Fortes e J ack Goody, que - mais o segundo que o primeiro - estudaram campos estruturados em torno de regras ambíguas e princípios conflitivos, nos quais os indivíduos competem, procurando maximizar seu status, prestígio, poder ou influência.

\section{0 ator racional}

Falta demonstrar, então, a influência profunda dessas tradições no trabalho de Barth, a qual se traduz em uma primazia do ator racional como recurso conceitual e metodológico. Tal influxo pode ser percebido não 
apenas na conceituação da etnicidade, revelando-se uma constante em todas as análises barthianas. Isto pode ser comprovado mediante os exemplos do parentesco, da liderança política e da teoria da etnicidade.

Em seu estudo sobre a aliança entre os curdos (1954), Barth descreve o casamento preferencial com a prima paralela patrilateral (FBD). As normas costumeiras expressam essa preferência de forma explícita. Considerando-se uma determinada mulher, seus primos paternos são os que têm mais direito a se casar com ela. Esse nível de "endogamia" mostrase tão apropriado do ponto de vista da etiqueta quanto conveniente do ponto de vista da economia da linhagem, pois conserva em seu interior, sem divisões, a totalidade da propriedade familiar. Como "privilégio consensual", esses primos pagam um preço menor pela noiva. Barth apresenta provas estatísticas para corroborar a alta freqüência da aliança com as primas (Barth 1954:167).

M uito bem. O norueguês pergunta-se então por que Ego, quando quer casar sua filha (a qual, diga-se de passagem, não tem lá muita free choice neste caso), "decide" seguir o costume, "dá-la" a seu sobrinho e baixar seu preço, embora pudesse perfeitamente "ganhar mais" com a transação, entregando-a a outra pessoa. Em suma, o que ganha Ego ao perder dinheiro, dando sua filha a seu BS? A resposta está no reforço dos laços entre ele e seus sobrinhos, na manutenção da solidariedade da linhagem paterna: “O pai da noiva, ao dispensar o filho de seu irmão de pagar o preço da noiva, cria uma obrigação e faz com que este deva apoiá-lo politicamente [...]. Esta transação pode, então, ser pensada como um tipo de troca diferida" (Barth 1954:168). O argumento parece, assim, ser uma peça da mais pura ortodoxia funcionalista. Observe-se, contudo: aquilo que na teoria clássica aparecia como uma necessidade estrutural, como um requisito do "sistema" (o reforço durkheimiano do laço social), traduz-se aqui em motivações pessoais, cálculos de ganhos a longo prazo, buscas de benefícios individuais por parte dos curdos ${ }^{13}$.

O deslocamento em direção ao indivíduo intensifica-se em trabalhos posteriores. Em um estudo publicado em 1989, Barth analisa a prática da tecnonímia. Quando os balineses usam tecnônimos,

[...] empregam tal costume para agradar aos orgulhosos progenitores do primogênito recém-nascido, dando atenção particular a um evento pessoal a que esses dêem muito valor. Mais tarde, usando tal nome, remeterão a esse tempo feliz e, ao mesmo tempo, por meio da recordação comum, evocarão certo sentimento de camaradagem (Barth 1989:136). 
Diferentemente do caso curdo, com cuja interpretação podemos concordar em alguns pontos, essa análise em termos tão ingênuos de psicologia individual me parece inaceitável ${ }^{14}$. Conforme ensina a história da antropologia, o sentido de uma norma não se pode esgotar nas expectativas explícitas nem nas intenções conscientes de seus praticantes. Por exemplo, não é preciso adotar as perspectivas holísticas (mas contrastantes) de um Radcliffe-Brown ou um Lévi-Strauss para nos darmos conta de que os membros de uma sociedade na qual se pratica o casamento de primos cruzados podem fazê-lo com uma assombrosa regularidade estatística e, ao mesmo tempo, declarar com total desenvoltura que se casam com quem quiserem. Da mesma maneira, não é incomum, mas extremamente freqüente, o fato de os membros de um grupo que pratica a residência uxorilocal "explicarem" tal norma como um período de prova para o novo esposo-genro. Em ambos os casos, as explicações nativas não esgotam o "sentido" das normas. Segundo os eventuais caprichos das distintas teorias, o significado de um costume pode ser elucidado por meio de suas relações com outros "aspectos" do próprio sistema de parentesco (noções sobre a filiação e a descendência, a onomástica, as práticas de residência, o emprego da terminologia classificatória), com outros aspectos da mesma cultura (práticas rituais, atividades produtivas, a língua) ou, inclusive, com as culturas das sociedades circundantes (como em certas análises de inspiração estruturalista). Em definitivo, trata-se de relacionar um fato com uma série tão longa quanto possível de razões de ordem geográfica, simbólica, ecológica, econômica ou histórica, que se impõem ao indivíduo - mas, certamente, jamais de basear a explicação naquilo que os atores crêem ou desejam que o dito fato seja.

O segundo exemplo ao qual vou referir-me é a análise barthiana da liderança política. A liderança pathan apóia-se, tal como no caso do parentesco, na utilização pessoal dos ciclos de reciprocidade (Barth 1990). $\mathrm{O}$ chefe provê comida, alojamento e diversão a seus seguidores. Em troca, estes Ihe devem leal dade política. Para Barth, o líder não estabelece vínculos com sua clientela de uma maneira generalizada e homogênea, mas por meio de uma multiplicidade de relações individuais, "contratos" informais diádicos. Cada seguidor decide se contrata, e com quem contrata. Não existe a priori um princípio histórico, geográfico e menos ainda estrutural com base no qual se possam antecipar as razões pelas quais certo cliente se filia à facção de determinado líder. Assim, os chefes vêemse envoltos em uma constante competição, não só pela honra, pela reputação, poder e prestígio, mas também pela quantidade e qualidade de suas clientelas. Barth é taxativo: "O sistema político de Swat, assim, não 
define um jogo de posições estruturais: surge do resultado das opções individuais" (1990:4). É tão claro, tão evidente o reinado explicativo da free choice do ator, que me devem perdoar a longa citação:

Os indivíduos são capazes de planejar e realizar opções em termos de um interesse privado e uma carreira política pessoal. Neste ponto, a vida política de Swat lembra a das sociedades ocidentais. M uitos dos indivíduos politicamente ativos em Swat reconhecem a distinção entre o benefício privado e o grupal; e, quando se defrontam com uma decisão determinada, tendem a considerar o primeiro acima do segundo [...]. Assim, o sistema de autoridade em termos de relações de dominação e de submissão, como também de recrutamento das pessoas nos grupos - constrói-se e se mantém mediante o exercício de séries contínuas de escolhas individuais (1990:2; ênfases minhas).

A postura é clara: em um contexto em que todos os atores perseguem suas metas individuais, a "perspectiva política" é só "um marco de meios e fins, dirigido a reunir partidários em busca de certas metas desejadas". A lealdade, em conseqüência, "não se concebe tanto como algo a se oferecer a um grupo, mas como o que os indivíduos dão em troca de outros benefícios" (Barth 1990:2). Barth chega inclusive a afirmar: "Todas as relações que implicam dominação são relações diádicas e de natureza voluntária ou contratual" (1990:2) ${ }^{15}$. A política consiste na arte de manipular ou canalizar essas relações diádicas para criar clientelas, facções ou grupos efetivos de seguidores (1990:3).

Em outro de seus livros, Barth afirma que, entre os nômades basseri, "todo o acampamento" decide diariamente, por consenso, aonde se trasladar ou quando migrar. A tomada de decisões "é um dos processos sociais fundamentais da sociedade nômade" (Barth 1986:43). Mas os prazeres da free choice não parecem repartir-se de forma igualitária, e alguns descobrem terem mais direito ou força que outros para respaldar suas decisões. Por exemplo, sustenta-se que "a autoridade interna na família basseri é muito similar à da família ocidental” (1986:15). Contudo, apenas uma página depois, afirma-se: "O levirato e o sororato são praticados quase sem exceção, mesmo contra a vontade das mul heres envolvidas" (1986:33). E descobrimos também que, na vida cotidiana, as transações, as negociações, a cooperação e o intercâmbio ocorrem, mais que entre o homem e a mulher basseri, entre o homem e seus afins masculinos (1986:34).

O terceiro campo a revelar a primazia do ator racional é, finalmente, a teoria da etnicidade. Como afirmei, apesar do que normalmente se pen- 
sa, a idéia do contato, do contraste ou da relação com os Outros como base da identidade grupal não é nova. Atestam-no Evans-Pritchard e suas célebres linhas sobre o conceito de cieng; Louis Dumont e seu trabalho sobre as castas e as ideologias modernas; e uma legião de estudos estruturalistas (Dumont 1987; 1975a; 1975b; Lévi-Strauss 1971)16. Não só a noção de identidade relacional foi cunhada muito mais cedo do que a teoria barthiana da etnicidade pretende insinuar, como seu próprio autor já a empregava antes de dar a conhecer sua aclamada "Introdução". No estudo do parentesco, "devemos levar em conta a confrontação 'nós-eles' contida na interação social e investigar como a experiência de quem são 'eles' molda a concepção que o ator tem de 'nós'” (1973:6), afirmava Barth, em um trabalho incluído no Festschrift para M eyer Fortes.

Definitivamente, a idéia da identidade relacional não é uma descoberta. Não obstante, a novidade da teoria barthiana está na razão pela qual a identidade se "ativa" ou não em determinados contextos. O argumento é simples. Em certos contextos, a "expressão" da etnicidade mostra-se inconveniente: “A fidelidade a normas de valor básicas não se poderia sustentar em situações em que, comparativamente, a própria conduta é totalmente inadequada" (Barth 1976a:31). Em bom português: às vezes, não convém mostrar a identidade étnica. $O$ meio impõe uma espécie de "seleção natural" dos diacríticos, e com isso retornamos mais uma vez à racionalidade dos custos e dos benefícios, ao cálculo de instrumentos e fins, às opções, às estratégias e às escolhas dos atores individuais. A conduta pública deve ser avaliada em estreita relação com as alternativas disponíveis no ambiente. Este é o corolário metodológico. Compreender a etnicidade é compreender seu contexto. Ou melhor, os contextos responsáveis, em cada caso particular, por requerer, permitir, tolerar ou diretamente negar sua expressão: “U ma compreensão dos mecanismos reguladores da identidade étnica pathan depende de uma compreensão dos fatores especiais que, em alguns casos, determinam a insustentabilidade da conservação dessa identidade e a falta de incentivos a ela" (Barth 1976b:161). Barth formula sua lei sociológica da seguinte forma:

Esta identidade só pode ser conservada caso se possa consumar de forma moderadamente satisfatória; do contrário, os indivíduos renunciarão a ela, em favor de outras identidades, ou a alterarão mediante uma modificação das normas para a atribuição da identidade (1976b:173-174; ênfases minhas).

Tentei demonstrar que, na maioria das situações, é vantajoso para os atores trocar sua etiqueta étnica com o fim de evitar o preço do fracasso; assim, on- 
de existe uma identidade alternativa ao alcance, o resultado consistirá em um trânsito de pessoal de uma identidade a outra, embora não se efetue alteração alguma nas características de status (1976b:175; ênfases minhas).

Revisemos um exemplo concreto. Na fronteira sul de Swat, os Pathan interagem com os Baluche. Se os primeiros se organizam em grupos de descendência localizados, os outros o fazem em chefaturas. As parentelas pathan possuem uma estrutura dificilmente permeável ao recrutamento de estranhos; as chefias baluches, fluidas e elásticas, incorporam com avidez novos membros (Barth 1976b:161-162). Conseqüentemente, um indivíduo ou um grupo pathan que se desligue de seus vínculos sociais optará por se assimilar à estrutura política baluche, em vez de ficar só (1976b:163). No leste, são outras as razões da fluidez étnica: ali os Pathan devem tratar com governos fortes e centralizados, que recompensam a diplomacia, a submissão e o compromisso, castigando a desobediência e a adesão a uma cultura considerada arcaica e ridícula: "continuar pretendendo ser pathan não Ihes dará vantagem alguma" (1976b:169). Finalmente, no norte, os Pathan também abandonam sua identidade étnica, embora por motivos distintos: assimilando-se aos Kohistani, conseguem certo respeito e alguma independência (1976b:170172). No primeiro caso, busca-se segurança; no segundo, o ingresso em uma sociedade percebida como mais poderosa e rica em oportunidades; no terceiro, tranqüilidade e certa autonomia. As causas e os objetivos mudam, mas, para o pathan desafortunado, o procedimento é sempre o mesmo: observando que sua identidade Ihe traz determinados problemas, estuda e avalia as alternativas disponíveis e, finalmente, opta pela mais proveitosa delas. Barth não vê inconveniente algum no fato - e, por vezes, o celebra - de que a etnicidade acabe sendo unicamente a capacidade de $o$ ator se livrar dela quando lhe convier.

A linguagem é mais que reveladora: os atores barthianos passam seus dias "escolhendo", "optando", "negociando", "avaliando", “calculando" e "maximizando" (Barth 1954; 1959; 1967; 1976a; 1976b; 1986; 1990). Quando se trata de conceber a ação em sociedade, Barth apela para a liberdade ou a racionalidade absolutas do indivíduo que, calculadora na mão, avalia criticamente os custos e os benefícios de cada um de seus atos ${ }^{17}$. A obra do norueguês é, inteira, uma invocação ao ator racional, uma defesa das razões e dos contextos de sua ação. 


\section{A concepção interacionista da sociabilidade}

Finalizemos destacando como essa ênfase metódica na onipotência do ator se traduz, com facilidade alarmante, em uma concepção interacionista do laço social. Adam Kuper observou como Barth, "um dos melhores alunos de Leach, desenvolveu outro tema, dirigindo sua atenção para as estratégias individuais e para a manipulação dos valores, e elaborando um modelo 'transacional' das relações sociais" (Kuper 1983:166). Firth distinguia conceitualmente a "estrutura social" (o sistema de constrangimentos institucionais, simbólicos e de conduta que limitam as opções do indivíduo) da "organização social" (o resultado concreto das escolhas feitas pelos atores, de acordo com tais limitações). Não satisfeito em privilegiar claramente a segunda instância, Barth leva o raciocínio um passo além, tratando-a como "causa" da primeira: "Considero razoável pensar as instituições ou os costumes sociais como a agregação complexa de numerosos microeventos de conduta, baseados em decisões individuais mediante as quais cada pessoa tenta enfrentar a vida" (1973:5). As opções e as escolhas cotidianas dos indivíduos ("organização social") acumulam-se e constituem, no próprio processo da interação, os novos laços sociais ("estrutura social" "18. É claro que para ele as decisões e as ações dos indivíduos são a "causa" direta da sociedade. As pessoas "criam" o significado do étnico na interação social, ou melhor, em cada interação ${ }^{19}$. O significado, nessas ocasiões, se "ajusta" reciprocamente segundo as expectativas mútuas, ou melhor, se negocia20. Não surpreende que Barth tenha dedicado pesquisas específicas ao problema dos entrepreneurs, promotores privilegiados - em sua opinião - da mudança social (Barth 1967).

No caso particular da etnicidade, Barth dá especial ênfase aos aspectos subjetivos ou voluntaristas da ação: trata-se claramente de uma questão de autodefinição (um fator subjetivo) e, no melhor dos casos, de definição por parte dos outros (um fator, no máximo, intersubjetivo). Fora a inoperante ecologia, não há notícia de fatores objetivos, restrições, condicionantes, coerção, coação. Asad critica Barth com razão: "Sua idéia de organização não é mais que o funcionamento, em um nível superior, do mesmo tipo de conduta contratual e maximizadora do indivíduo" (A sad 1972:79).

O curioso é que Barth poderia ter interpretado a crítica de Asad como um elogio. Em 1967, nosso autor já postulava que se deve estudar a mudança social e não a institucionalização (em termos mais modernos, o processo e não a forma; nos termos de Firth, a organização social e não a estrutura social). A mudança social não é algo abstrato, mas perceptível na ação dos indivíduos. É inútil formular hipóteses sobre as "metas", as 
"utilidades" ou as "funções" das sociedades, como fazia Radcliffe-Brown. Tampouco é de grande serventia rastrear uma suposta racionalidade do sistema, como pretendia Parsons. O laço social cria-se nas decisões cotidianas, nas transações particulares entre indivíduos concretos que calculam, julgam e avaliam os resultados de suas ações. A sociedade é uma mera adição, um agregado estatístico, um epifenômeno das interações particulares. Os homens "criam" ou "constroem" seu próprio mundo e, conseqüentemente, o modelo para explicá-lo deve ser "gerativo":

Devemos incorporar em nosso modelo de como a cultura é gerada tanto um olhar dinâmico sobre a experiência, resultado da construção de eventos pelos indivíduos, como um olhar dinâmico sobre a criatividade, resultado da luta dos atores para superar a resistência por parte do mundo (Barth 1989:134).

M ais especificamente, a sociedade é a soma e a repetição das ações ou construções "bem-sucedidas". Barth supõe que a "sociedade" esteja na mente dos indivíduos concretos, na forma de metas, objetivos, valores, necessidades, expectativas. A ação social é precisamente a satisfação ou o cumprimento de tais necessidades em um meio de interação, competição, cooperação ou antagonismo: “as pessoas decidem participar de um grupo, levando em conta as recompensas que esperam obter [...] se as recompensas forem grandes, pode-se esperar que esse comportamento seja imitado por outros; se, por seu turno, os resultados não forem desejáveis para o ator, não haverá imitação" (Barth 1967:668). O sentido do étnico negocia-se em cada interação, quase como uma transação entre iguais. À exceção dos fatores ecológicos e demográficos ou das mútuas expectativas dos atores, não há estrutura ou condição externa a limitar, obstruir ou sequer perturbar a plena soberania das partes.

\section{Palavras finais}

Talvez a prova mais contundente da importância da teoria barthiana da identidade étnica seja a quantidade de defesas e críticas granjeadas ao longo do tempo. Trata-se, sem dúvida, de um marco na teoria antropológica. É indiscutível sua relevância na fundamentação teórico-metodológica da etnicidade (Wallman 1991; Briones e Siffredi 1989; Cohen 1978) nas pesquisas sobre suas implicações pragmáticas ou políticas (M orin e Saladin D'Anglure 1997; Fenton 1999) e, inclusive, nos estudos de caso (Skar 1997). M as justamente por sua enorme difusão, vejo-me obrigado a 
opor-Ihe alguns reparos. As formulações barthianas encobrem - ou meIhor, sustentam-se sobre - uma peculiar concepção das relações entre o ser humano e sua vida em sociedade. Não podemos aceitar sem mais a idéia de um ator que "opta" ou "escolhe" em cada contexto uma identidade étnica, para abandoná-la tão logo ela Ihe resulte inconveniente ${ }^{21}$.

Em primeiro lugar, seria possível invocar com facilidade casos empíricos nos quais indivíduos ou grupos se aferram à sua identidade étnica, mesmo quando isso Ihes causa problemas. A etnicidade pode também expressar, voluntária ou involuntariamente, o status "inferior" de uma minoria em face de uma maioria, sem ser abandonada, apesar de sua inconveniência estratégica.

Em segundo lugar, Barth descreve uma espécie de jogo de autodefinição, no qual as opções "étnicas" expressariam a "identidade geral mais básica". A pesar de se ver forçado a reconhecer que a identidade étnica é “imperativa" (1976a:20), nosso autor não desenvolve esse tema. Paradoxalmente, pressupõe, assim, um ator que calcula e racionaliza, mas que, ao mesmo tempo, carece de memória e deve enfrentar a penosa tarefa de começar do zero em cada interação, sendo incapaz de passar das imprecisões iniciais de cada encontro com o O utro a algum tipo de avaliação, indução ou expectativa generalizada, apta a servir - ou condicionar suas interações futuras.

Pela mesma razão, deve-se relativizar a tese de que o ator calcula custos e benefícios antes de empreender qualquer ação. Como assinala Weber, não é comum encontrar um ator que oriente sua conduta exclusivamente por um cálculo racional de meios e fins. Efetivamente, as decisões concernentes à etnicidade - como qualquer outra ação social - podem responder a tal cálculo, mas também podem obedecer a uma motivação valorativa, afetiva ou tradicional, ou mais provavelmente a uma mistura de todas elas (Weber 1996:20). Não se pode ignorar o fato de que as expectativas, as metas e as motivações "pessoais" se encontram coletivamente condicionadas. Como se sabe desde Freud, Durkheim, M arx e Nietzsche, as "opções" e as "escolhas" dos indivíduos não se fazem em um vazio psicológico e muito menos em um vazio sociocultural. Poderse-á recorrer às categorias de Durkheim e M auss, à ideologia marxista ou mesmo aos jogos de oposições mentais com que se deleitam as teorias de inspiração estruturalista, mas em todo caso a conduta humana encontra-se sempre sujeita a algum tipo de condicionamento. A idéia de uma vontade ou uma racionalidade imperturbada e imperturbável, a reger com exclusividade os destinos do ator individual, é, tudo leva a crer, tãosomente uma ilusão. 
Em terceiro lugar, o fato de a etnicidade ser "negociada" não a impede de poder se voltar contra os atores, "congelando" certos diacríticos que - embora Barth não o queira reconhecer - se sedimentam como requisitos sine qua non de pertencimento grupal. Os grupos étnicos reinventam-se, e não pretendo negar tal afirmação, mas isso não é incompatível com a idéia de o fazerem com base em condições transmitidas, institucionais, tradicionais, que podem ser variáveis, mas que existem e se impõem às dinâmicas de pertencimento étnico. $O$ argumento do norueguês é, com isso, conduzido de volta a seu incômodo princípio. A teoria da etnicidade não se pode basear somente no momento "criativo" (e carismático) da constituição das fronteiras étnicas, mas deve também contemplar, necessariamente, o processo de "institucionalização" desses limites. Isso nos leva a um novo problema. Os grupos dedicados a "negociar" suas estratégias em cada interação geralmente não dispõem, todos, dos mesmos recursos para fazê-lo: alguns são mais iguais que outros e têm mais possibilidades de materializarem as identidades que Ihes convierem ${ }^{22}$. Barth chega a indicar essa condição, mas apenas insinuando-a acanhadamente em suas obscuras "leis ecológicas". A etnicidade é um processo ancorado em condições históricas concretas. Os grupos sociais imersos em um mesmo ambiente de competição nem sempre são "simbióticos" ou "complementares", e entre eles há desigualdades de poder impossíveis de serem ignoradas caso se pretenda revelar como se fixam suas respectivas identidades (Fenton 1999; Briones e Siffredi 1989)23.

Ao defender até as últimas conseqüências a primazia do ator, ao combater os enferrujados fantasmas do funcionalismo, ao ignorar deliberadamente os sistemas, as estruturas, as hierarquias e todas as restrições possíveis, parece que Barth perdeu algo pelo caminho. Não se pode escapar a uma coerção excessiva simplesmente ignorando-a, nem a etiquetando como "ecologia". Em um modelo no qual a free choice do ator individual reina soberana na hora de explicar a ação, tudo faz crer que a ecologia entra pela janela, para salvar a falta de condicionantes sociais ou estruturais - um recurso quase desesperado para estabelecer algum tipo de limite em situações nas quais a mera "transação" , a "escolha" ou a "negociação" entre os grupos étnicos ou os indivíduos não bastam para compreender problemas sociológicos concretos. 
Diego Villar é pesquisador-bolsista do Consejo de Investigaciones Científicas y Técnicas (CONICET), Argentina. E-mail: «dvillar@fullzero.com.ar

\section{Notas}

* Agradeço aos senhores Pablo Sendón e J osé Braunstein, e também a um parecerista anônimo de $\mathrm{M}$ ana, por seus valiosos comentários a uma primeira versão deste artigo.

1 Quarenta na edição em espanhol; na edição original inglesa são apenas 29.

2 Os fatos empíricos que sustentam essas afirmações são os que nosso autor repetiria - integral mente, sem retoques nem pruridos - em seu posterior e menos ignorado estudo sobre a identidade dos Pathan (Barth 1976b).

3 Podemos perguntar que sociedade não ilustraria esse postulado. Desde as velhas polêmicas sobre o totemismo australiano, sabemos que, em cada sociedade, as formações simbólicas negam, afirmam, projetam, refletem (preencher as lacunas com o verbo que se queira) certas imagens do ambiente; ou, em termos lévi-straussianos, que o "bom para pensar" tem algo a ver com o "bom para comer". Não é apenas lógico, mas totalmente previsível, que os Nuer e os Dinka, povos eminentemente pastoris, abundem em símbolos relacionados ao gado. Mas isso não é tudo. Por trás da insistência nos fatores "técnicos", "materiais" e "adaptativos" como veículos privilegiados do simbolismo ritual, Barth afirma que, ao terminar a sedentarização forçada sofrida pelos Basseri, muitos deles decidiram voltar à rotina nômade, "apesar de isso não lhes convir em termos de custos e benefícios". Em última instância, pois, as próprias migrações não podem ser compreendidas por razões adaptativas ou utilitárias, e sua explicação profunda deve ser rastreada em sua forma "dramática" e plena de "sentidos implícitos" (Barth 1986:153). Ou, em outras palavras, mediante uma leitura antropológica tradicional; com isso, todo o barulho em torno de uma "perspectiva ecológica" se mostra desconcertantemente despropositado.

4 Por exemplo, note-se a ambivalência dessa frase: "Para os Basseri, investir trabal ho em qualquer coisa que não seja cuidar dos animais ou satisfazer as necessidades imediatas para acomodar os membros do grupo doméstico requereria formas de organização inexistentes entre eles" (Barth 1986:101).

5 Recordemos uma vez mais os Nuer e os Dinka de Evans-Pritchard e Godfrey Lienhardt, trabal hos em que a atenção dada ao papel do gado supera largamente a extensão descritiva, o peso explicativo e a qualidade interpretativa das te- 
ses ecológicas de Barth. Estudos ainda mais antigos, como o de M auss e Beuchat sobre os esquimós, concedem à ecologia uma importância igual ou superior à encontrada nas monografias barthianas. Qualquer americanista se pode perguntar o que o enfoque de Barth tem de especificamente "ecológico", se comparado a certos trabalhos de Philippe Descola ou, ainda, à hoje mais ou menos furtiva, mas sempre infatigável, "ecologia cultural” norte-americana. É quase desolador se ver o próprio Barth reconhecer, no prólogo de sua etnografia basseri, quando revela as motivações para adotar a "orientação ecológica" , que "algumas razões poderiam ser subjetivas e refletir mais as necessidades pessoais do pesquisador que os requisitos analíticos do material [...] algumas facetas da vida nômade se mostram tão surpreendentes para um membro de uma sociedade sedentária [...]" (Barth 1986).

6 Pablo Sendón sugeriu uma leitura alternativa da ecologia barthiana, localizando-a dentro do amplo espectro de estudos sobre sociedades pastoris, no qual a "ecologia cultural" goza ainda de grande predominância. N esse contexto, o modelo do norueguês opõe-se aos enfoques redutores que vêem na ecologia o determinante todo-poderoso da conduta humana; e, em conseqüência, o que interpretamos como uma inconsistência pode ser pensado como uma vantagem explicativa (ver Khazanov 1994).

7 Conforme assinala Goody, a distinção - virtualmente inexistente nas ciências sociais anglo-francesas - entre "sociedade" e "cultura" é tipicamente parsoniana (1995:146). Como comprovaremos, o fato de Barth ter sido aluno de Parsons teve suas conseqüências.

${ }^{8}$ Chama a atenção - mais ainda em um discípulo de Parsons e em alguém que denuncia "falhas de lógica" (Barth 1976a:12) no ol har alheio - a surpreendente interpretação barthiana das “tipologias" e dos “tipos ideais" (1976a:11, 13, 24, 36). Caso se tratasse de um "tipo" weberiano em sentido estrito, a equação uma terra = uma etnia = uma cultura = uma língua não seria uma síntese indutiva a reunir as características que certos grupos devem ter para serem qualificados de "étnicos" (em suma, a acepção de sentido comum: temos uma definição geral e vemos logo se o caso particular se "encaixa" nela). Tratar-se-ia, pelo contrário, de um recurso heurístico, de uma construção metodológica que exacerba certos traços do fenômeno para logo cotejar com ela o caso particular, do qual se busca apreender a singularidade. Tendo em mente preocupações comuns a Dilthey, Windelband, Rickert, Sombart e Simmel, a sociologia weberiana buscava esclarecer a singularidade, não a generalidade do fenômeno ou a "individualidade" (e não o indivíduo) que se considerava em cada caso (Weber 1993; Bendix 1960; Parsons 1968; Aron 1985).

9 Por exemplo, a tese da brilhante monografia sobre os líderes pathan é a de seu constante recurso à free choice a despeito de todas as restrições imagináveis: página após página, desfilam ocasiões em que os Pathan ignoram olimpicamente a descendência, a aliança, a localidade, a exploração, a sociedade colonial e todo limite concebível, fazendo a cada momento o que Ihes dá vontade (Barth 1990). 
10 O nome de uma dessas teorias é revelador: egonomics (ver Elster 1997: esp. 37-109).

11 “Foi a insistência no indivíduo vivo, ativo e dedicado ao cálculo que deu às monografias de $M$ alinowski sua vitalidade e as fez contrastar de maneira notável e inovadora com o trabalho de outros antropólogos" (Kuper 1983:27).

12 Um dos argumentos mais famosos de Leach centra-se na competição feroz entre indivíduos que procuram obter ou maximizar seu poder político (1954:10).

13 Pessoalmente, preferiria distinguir entre os níveis sociológico e individual da "causalidade". Esquecendo os astutos ensinamentos malinowskianos sem falar de $\mathrm{O}$ suicídio, de Durkheim - , Barth limita sua explicação às racionalizações explícitas e declaradas dos sujeitos. No entanto, talvez sem perceber, afirma, pouco depois, que "os jovens tomam a decisão correta, mesmo quando subjetivamente pareçam sentir, e invariavelmente afirmem, que são inteiramente livres para buscar cônjuges onde quiserem" (Barth 1954:168). Esta "correção", precisamente, clama por uma explicação sociológica.

14 Não é preciso recordar aqui as críticas feitas por N eedham (1962) às tentativas de explicar o parentesco em termos de psicologia individual. Só acrescentarei, a título de defesa da disciplina, que o próprio Edward Tylor, já em 1889 (cem anos exatos antes do artigo de Barth), tentava explicar a tecnonímia, pondo-a em relação com outros aspectos dos "sistemas" de parentesco e com instituições sociais como a uxorilocalidade e a evitação ritual dos sogros (Tylor 1889).

15 Barth tem o costume de estender a comparação econômica a todo tipo de relação concebível. Mas teria sido bom que indicasse de modo preciso com que noção de "economia" ou "mercado" ele está trabalhando. Barth sabe perfeitamente que, ao receber remuneração, um pathan automaticamente se reconhece como inferior a quem Ihe paga (Barth 1990:42-ss.). A complementaridade entre um líder e seus seguidores não implica simetria e, havendo dominação de qualquer tipo, falar de free choice parece-me uma quimera. Na monografia basseri, nosso autor vê, no vínculo entre um pastor e seus servidores, "um contrato econômico explícito" (Barth 1986:21). Embora as tarefas pastoris em questão sejam evidentemente "produtivas" ou "econômicas", não se busca um indivíduo qualquer para executá-las. Não pode ser - e Barth o reconhece - nem um outsider nem um parente demasiado próximo; se um casal é estéril e não tem filhos, buscará o BS do marido. A questão do trabalho, à primeira vista puramente econômica, implica também uma preferência, uma escala de sociabilidade ou ao menos uma conceituação valorativa dos graus parentais de proximidade/distância. Em todos esses casos, as metáforas economicistas da ação social parecem imprecisas.

16 É possível que algum lingüista acrescente não ser façanha alguma afirmar que o "sentido" de algo é relacional, sobretudo meio século depois de Saussure. 
17 Ao menos um autor levantou a voz para criticar a ideologia e o etnocentrismo implícitos nesse tipo - tão anglo-saxão - de visão da humanidade (Dumont 1987; 1975a). Talal Asad identificou, na concepção barthiana do ser humano, reminiscências do homo homini lupus de Thomas Hobbes (1972:80-82). Na monografia escrita a partir das notas de campo de Pehrson, por exemplo, Barth não consegue evitar a projeção de sua peculiar antropologia sobre os M arri Baluch, sugerindo que sua imagem do ser humano consiste em “uma criatura má, egoísta e oportunista" (Barth 1966:27).

18 Em trabalhos posteriores, Barth defendeu uma "convergência" com as teorias que enfatizam a chamada "construção social da realidade" (1989:123). A terminologia de Barth aparentemente muda mais que suas idéias: nesse mesmo artigo, a "sociedade plural" de Furnivall transformou-se em "sociedade complexa" (Barth 1989:124).

19 Asad acredita coexistirem em Barth duas tendências em uma tensão não resolvida: o "funcionalismo clássico" e os "estudos modernos interacionistas" (1972:93). Não estou de acordo: em Barth, a segunda tendência sobrepujou — e muito - a primeira.

20 Segundo certa crítica, esse tipo de conceituação “individualista e contratual" traz implícitas todas as premissas ideológicas do livre mercado e do capitalismo (Asad 1972:80). As próprias descrições barthianas revelam haver "Iaços de solidariedade entre os membros das classes exploradoras e exploradas, entre os que podem exercer uma opção política significativa e aqueles que não o podem. Por isso, trata-se de relações diferentes das que definem um sistema de mercado puro, no qual o comprador individual, em sua busca incessante de benefícios, lida com o vendedor individual como um igual em termos de direitos e obrigações" (Asad 1972:85).

21 Os enfoques "instrumentalistas" não só herdaram esses dilemas, como os exploraram até o limite. Os grupos étnicos são só grupos de interesse. J á não interessa se as fronteiras étnicas existem ou como se produzem: importam somente as razões pelas quais “convém” ou não ativá-las (Briones e Siffredi 1989).

22 Nas palavras de Asad: “Em lugar de uma organização dependente das opções políticas de todas as pessoas (i.e., uma organização criada por meio de transações voluntárias e individuais entre os que buscam apoio político e aqueles que o podem prover), encontramos uma estrutura na qual as escolhas políticas da maioria são em boa medida ilusórias ou irrelevantes" (1972:90).

23 Na verdade, Barth posteriormente modificou sua postura em certo sentido: os atores - que continuam sendo onipotentes - agora estão "posicionados" (1989:134). 


\section{Referências bibliográficas}

ARON, Raymond. 1985. Las etapas del pensamiento sociológico. Buenos Aires: Siglo Veinte.

ASAD, Talal. 1972. "Market model, class structure and consent: a reconsideration of Swat political organization". Man, 7(1):74-94.

BARTH, Fredrik. 1954. "Father's brother's daughter marriage in Kurdistan". Southwestern J ournal of Anthropology, 10(2):164-171.

. 1956. "Ecologic relationships of ethnic groups in Swat". A merican Anthropologist, 58(6):1079-1089.

1959. "Segmentary opposition and the theory of games: a study in Pathan organization". J ournal of the Royal Anthropological Institute, 89:5-21.

. 1966. “Preface”. In: R. N. Pehrson, The social organization of the Marri Baluch (compiled and analyzed from his notes by Fredrik Barth). Chicago: Aldine Publishing Company. pp. vii-xii.

. 1971. "The system of social stratification in Swat, North Pakistan". In: E. Leach (ed.), Aspects of caste in South India, Ceylon and NorthWest Pakistan. Cambridge: Cambridge University Press. pp. 113146.

. 1973. "Descent and marriage reconsidered". In: J . Goody (ed.), The character of kinship. London: Cambridge University Press. pp. 3-19. .1967. "On the study of social change". American Anthropologist, 69(6):661-669.

. 1976a. “Introducción”. In: F. Barth (org.), Los grupos étnicos y sus fronteras. México: Fondo de Cultura Económica. pp. 9-49. 1976b. “Los patanes: su identidad y conservación". In: F. Barth (org.), Los grupos étnicos y sus fronteras. M éxico: Fondo de Cultura Económica. pp. 152-176.

1986 [1961]. Nomads of South Persia: the Basseri tribe of the Khamseh confederacy. Illinois: Waveland Press. . 1989. "The analysis of culture in complex societies". Ethnos, 54(3-4): 120-142.

. 1990 [1959]. Political leadership among the Swat Pathans. London: The Athlone Press.

BENDIX, Reinhard. 1960. Max Weber. Buenos Aires: A morrortu.

BRIONES, Claudia e SIFFREDI, Alejandra. 1989. “Discusión introductoria sobre los límites teóricos de lo étnico". Cuadernos de Antropología, 2(3):5-24.

COHEN, Ronald. 1978. "Ethnicity: problem and focus in Anthropology". Annual Review of Anthropology, 7:379-403.

DUM ONT, Louis. 1975a. "Preface to the french edition of The Nuer". In: J . H. M. Beattie e R. G. Lienhardt (eds.), Studies in social anthropology. Essays in memory of E. E. Evans-Pritchard by his former Oxford Colleagues. Oxford: Clarendon Press. pp. 328-342. . 1975b. Introducción a dos teorías de la antropología social. Barcelona: Anagrama.

1987. Ensayos sobre el individualismo. Una perspectiva antropológica sobre la ideología moderna. Madrid: Alianza.

ELSTER, J on. 1997. Egonomics. BarceIona: Gedisa.

FENTON, Steve. 1999. Ethnicity, racism, class and culture. London: MacM illan. 
FIRTH, Raymond. 1949. "Authority and public opinion in Tikopia". In: M. Fortes (ed.), Social structure. Studies presented to A. R. RadcliffeBrown. Oxford: Clarendon Press. pp. 168-188.

FURNIVALL, J. S. 1991. "Plural economies". In: P. Worsley (ed.), The new modern sociology readings. Middlesex: Penguin Books. pp. 387-391.

GOODY, J ack. 1995. The expansive moment: anthropology in Britain and Africa 1918-1970. Cambridge: Cambridge University Press.

KHAZANOV, Anatoly. 1994. Nomads and the outside world. Wisconsin: Wisconsin University Press.

KUPER, Adam. 1983. Anthropology and anthropologists. The modern British school. London: Routledge and Kegan Paul.

LEACH, Edmund. 1954. Political systems of Highland Burma. London: Bell. . 1982. "Barth's empirical science: a review article". Ethnos, 47(3-4): 271-273.

LÉVI-STRAUSS, Claude. 1971. “Rapports de symétrie entre rites et mythes de peuples voisins". In T. O. Beidelman (ed.), The translation of culture. Essays to E. E. EvansPritchard. London: Tavistock. pp. 161-178.

MORIN, Françoise e SALADIN D'ANGLURE, Bernard. 1997. “Ethnicity as a political tool for indigenous rights". In: C. Govers e H. Vermeulen (eds.), The politics of ethnic consciousness. London: MacM illan. pp. 157-193.

NEEDHAM, Rodney. 1962. Structure and sentiment. A test case in social anthropology. Chicago: Chicago University Press.

PARSONS, Talcott. 1968. The structure of social action. A study in social theory with special reference to a group of recent European writers. New York: The Free Press.

SKAR, Harald. 1997. La gente del Valle Caliente. Dualidad y reforma agraria entre los Runakuna. Lima: Pontificia Universidad Católica.

TYLOR, Edward B. 1889. “On a method of investigating the development of institutions; applied to laws of marriage and descent". J ournal of the Royal Anthropological Institute, 18:245-272.

WALLMAN, Sandra. 1991. “Ethnicity and the boundary process". In: P. Worsley (ed.), The new modern sociology readings. Middlesex: Penguin Books. pp. 408-411.

WEBER, Max. 1993. Ensayos sobre metodología sociológica. A morrortu, Buenos Aires. . 1996. Economía y sociedad. México: Fondo de Cultura Económica. 


\section{Resumo}

O presente trabalho discute a abordagem de Fredrik Barth para o problema da etnicidade com base em uma análise abrangente de sua obra. Levam-se em conta algumas idéias-chave que aparecem de maneira recorrente nos escritos programáticos e teórico-metodológicos desse autor, bem como em seus estudos etnográficos. Analisa-se o poder explicativo dos fatores ecológicos e demográficos em seu modelo, a importância de sua tese da identidade relativa, a genealogia das influências teóricas encontradas nas explicações barthianas e o problema do ator racional como fio condutor de sua concepção interacionista das relações sociais.

Palavras-chave Barth; Etnicidade; Identidade; Teoria antropológica; Teoria sociológica

\section{Abstract}

This article discusses Fredrik Barth's approach to the problem of ethnicity based on a wide-ranging analysis of his work. Analysis focuses on various key ideas recurrent in the author's programmatic and theoretical-methodological writings, as well as his ethnographic studies. A critical evaluation is made of the explicatory power of ecological and demographic factors in his model, the importance of his thesis of relative identity, the genealogy of theoretical influences found in Barthian explanations and the problem of the rational actor as the binding element in his interactionist conception of social relations.

Key words Barth; Ethnicity; Identity; Anthropological theory; Sociological theory 